2 Francisco River basin, Brazil to balance hydropower and river

\title{
biodiversity tradeoffs
}

4

5 Jesse R. O’Hanley, ${ }^{1,2^{*}}$ Paulo S. Pompeu, ${ }^{3}$ Marina Louzada ${ }^{3}$ Ludimilla P. Zambaldi, ${ }^{4}$

$8 \quad{ }^{1}$ Kent Business School, University of Kent, U.K.

$9 \quad{ }^{2}$ Durrell Institute of Conservation and Ecology, University of Kent, U.K.

$10 \quad{ }^{3}$ Departamento de Biologia, Universidade Federal de Lavras, Brazil

$11{ }^{4}$ Instituto Federal de Minas Gerais, Brazil

$12{ }^{5}$ International Centre for Ecohydraulics Research, University of Southampton, U.K.

$14 *$ Corresponding author: Kent Business School, University of Kent, Canterbury, CT2 7FS, U.K.

15 Email: j.ohanley@kent.ac.uk; Tel. +44 1227824286

16

17 Running title: Optimizing hydropower \& river biodiversity

18

19 Keywords: sustainable development; hydropower planning; river connectivity; fish species 20 richness; migratory fish dispersal; optimization 


\section{Abstract}

22 To support eco-friendly hydropower planning in developing regions, we propose a spatial

23 optimization model for locating dams to balance tradeoffs between hydropower generation and

24 migratory fish species richness. Our model incorporates two special features. First, it is tailored to

25 the dispersal of tropical migratory fishes, which require long, unimpeded river stretches to

26 complete their life-cycle. To model fish with this type of dispersal pattern, we introduce the

27 concept of a river pathway, which represents a novel way to describe river connectivity. Second,

28 it combines decisions about dam placement and removal, thus facilitating opportunities for

29 hydropower offsetting. We apply our model to the São Francisco River basin, Brazil, an area of

30 hydropower-freshwater biodiversity conflict. We find that dams have reduced weighted migratory

31 fish richness $51 \%$ compared to a pre-dam baseline. We also find that even limited dam removal

32 has the potential to significantly enhance fish biodiversity. Offsetting the removal of a single dam

33 by the optimal siting of new dams could increase fish richness by $25 \%$ above the current average.

34 Moving forward, optimizing new dam sites to increase hydropower by $20 \%$, rather than selecting

35 the fewest number of dams, could reduce fish species losses by $89 \%$. If decisions about locating

36 new dams are combined with dam removal, then a win-win can even be achieved with $20 \%$ greater

37 hydropower and 19\% higher species richness. Regardless of hydropower targets and dam removal

38 options, a key observation is that optimal sites for dams are mostly located in the upper reaches of

39 the basin rather than along the main stem of the São Francisco River or its main tributaries. 


\section{Introduction}

41 Freshwaters are among the most sensitive to human development and the most threatened of all ecosystems (Dudgeon et al. 2006). Freshwater vertebrates have experienced severe declines in

43 spatial distribution and abundance (Strayer and Dudgeon 2010), with a 76\% average population

44 reduction over the past 40 years (WWF 2014). A principal cause of this decline is habitat loss

45 fragmentation due to the construction of dams (e.g., for irrigation, hydropower, and flood control) and other artificial in-stream structures (e.g., stream-road crossing).

47 Recent concerns about the effectiveness of traditional mitigation strategies, namely fish passes, challenge conventional wisdom (Brown et al. 2013). Fish passes often exhibit lower than expected

49 efficiencies (Noonan et al. 2012), unintended consequences (McLaughlin et al. 2013), or even

50 negative effects (e.g., the creation of "hotspots" for predation: Agostinho et al. 2012; and

51 ecological traps: Pelicice and Agostinho 2008). Part of this failure relates to an overly narrow focus

52 on technical standards, without considering local factors such as the presence of key fish habitats

53 above and below a pass (Pompeu et al. 2012) and downstream movement of embryos, larvae, and

54 adults past reservoirs (Pelicice et al. 2015). In North America and Europe, alternatives to fish 55 passes, such as complete or partial removal of fish migration barriers, are becoming more frequent.

56 With restoration efforts constrained by limited resources, however, effective methods to prioritize

57 removals at the catchment-scale are critical to achieve conservation objectives.

58 Various barrier prioritization methods have appeared in recent years (Kemp and O'Hanley 2010).

59 These include simple but inefficient scoring-and-ranking approaches (Kocovsky et al. 2009),

60 spatially informed graph theoretic models (Segurado et al. 2013), and optimization based 61 techniques (O’Hanley and Tomberlin 2005). Applications are biased, however, to developed, 62 northern temperate regions, where the majority of viable hydropower and water storage potential 
63 has already been realized. Installation of new infrastructure is rarely considered, though there are 64 exceptions (Ziv et al. 2012; Ioannidou and O’Hanley 2018). Existing methods also frequently 65 apply assumptions appropriate to a limited number of economically important fish taxa, usually 66 with anadromous migrations (e.g., Salmonidae). Unfortunately, such tools cannot be easily 67 transferred to tropical regions, which maintain rich fish communities with more complex life68 histories and movement strategies (Carolsfield et al. 2003; Hogan et al. 2004). There is an urgent need to develop prioritization methods for dam installation and removal that support more sustainable water and energy resource management in tropical regions.

Brazil provides a perfect illustration of a water-energy-fisheries nexus. Per capita income is increasing and rapid urbanization is placing strains on inadequate water and electricity distribution systems. More than $80 \%$ of electricity is produced from hydropower. There are plans to develop this resource further. In the Amazon alone, there are 256 hydropower dams $(\geq 1 \mathrm{MW})$ in operation, under construction, or proposed (Little 2014). While helping to reduce poverty and spur economic growth, rapid expansion of large-scale hydropower can negatively affect inland fisheries, a highly valuable ecosystem service in the country. Brazilian rivers are enormously productive and species rich, with well over 2000 identified fish species (Buckup et al. 2007). Since 2000, mean nonmarine capture fisheries in Brazil have exceeded 200,000MT annually (FAO 2012). Concerns over dam impacts on fisheries and biodiversity are likely to be a continuing source of environmental 81 conflict (Watkin et al. 2012).

This study describes the use of a novel spatial optimization model for locating hydropower dams to balance tradeoffs between hydropower generation potential and migratory fish species richness. A case study of the São Francisco River basin is used to explore various hydropower development scenarios and their impacts on riverine fish biodiversity. There are at least two noteworthy aspects 
of our model. First, whereas existing barrier optimization tools are designed exclusively for

87 migratory fish in northern latitudes (Kuby et al. 2005; Neeson et al. 2015; King et al. 2017), our model is tailored to the unique dispersal patterns of tropical migratory fish species. Such species generally require long, unimpeded stretches of free-flowing river to complete their life-cycle. To model fish with this type of dispersal pattern, we introduce the concept of a river pathway. The use of river pathways represents a novel way to describe river connectivity that contrasts markedly from existing river connectivity metrics. Second, current models focus exclusively on removal/mitigation of existing barriers (Neeson et al. 2015) or, in a limited number of cases, the

94 location of new dams (Ziv et al. 2012; Ioannidou and O’Hanley 2018). In contrast, our model combines both dam placement and removal decisions. This is particularly useful for investigating how hydropower offsetting could be used to achieve biodiversity gains, while maintaining or expanding hydropower generation potential (Owen and Apse 2015).

\section{Methods}

Study Area

100 The São Francisco (Figure 1) is the $25^{\text {th }}$ longest river in the world (Tan and Sheng 2004). The basin 101 covers $7.4 \%\left(631,133 \mathrm{~km}^{2}\right)$ of Brazil between latitudes $7^{\circ} \mathrm{S}$ and $21^{\circ} \mathrm{S}$ (Knoppers et al. 2006). 102 Primary water uses include power generation, irrigation, urban/industrial water supply, navigation, 103 and fishing. Downstream of Três Marias dam, floodplains along the São Francisco occupy 104 approximately $2000 \mathrm{~km}^{2}$ (Welcomme 1990), supporting one of the most important inland Brazilian 105 fisheries (Sato and Godinho 2004).

107 Since the 1950s, the São Francisco River has been dammed for energy generation and flow 108 regulation. Presently, there are 28 large $(\geq 30 \mathrm{MW})$ hydropower dams and dam complexes 
109 (hereafter dams) across the basin supplying 10.8GW of installed generation capacity. There are at

110 least 117 proposed development sites, which if built would provide an additional 3.9GW (+27\%)

111 of hydropower. The vast majority of these candidate sites are concentrated in the upper reaches of

112 the basin to the west and south.

\section{Migratory Fish Species Richness and Abundance}

114 In tropical areas, such as the São Francisco, migratory freshwater fish are mostly pelagic-broadcast

115 spawners. Each year, adults migrate upstream, sometimes hundreds or even thousands of

116 kilometers, to spawn and then migrate back downstream (Godinho and Pompeu 2003). Embryos

117 and larvae drift passively downstream until developing into free-swimming juveniles, before

118 eventually seeking out floodplains to complete their rearing. This is distinct from the spawning

119 strategies typical of migratory fish species in temperate areas (e.g., salmon, Oncorhynchus sp., and

120 sturgeon, Acipenseridae sp.), where fertilized eggs are actively deposited in (brood hiders) or

121 subsequently adhere to (benthic spawners) the substrate.

122 Tropical migratory fish usually require long stretches of river (10s to 1000 s of kilometers) with 123 unimpeded flow. The presence of dams, which block upstream migrating adults or cause

124 downstream dispersing embryos/larvae to drop out of suspension after encountering large 125 reservoirs, can cause rapid declines in species richness (Pelicice et al. 2015).

[Figure 2 approx. here]

127 We modeled richness for 12 native migratory fish species in the São Francisco as function of river

128 length (Appendix A). To do so, we introduce the concept of a river "pathway." A pathway is the 129 longest continuous stretch of river in the direction of flow unimpeded by dams or reservoirs. A 130 pathway is uniquely identified by its terminal upstream and downstream segments, starting either 
131 at the river headwaters or immediately downstream of a dam and ending either immediately above

132 the first downstream reservoir or the river mouth (Figure 1). Based on Zambaldi and Pompeu

133 (Under review), pathways were subdivided into three size classes and assigned species richness

134 estimates proportional to size (Table 1).

[Table 1 approx. here]

136 While river length is an important determinant of richness, access to floodplains, which provide 137 productive areas for juvenile rearing, has been shown to regulate migratory fish abundance 138 (Nestler et al. 2012). To incorporate the importance of floodplain access, we estimated floodplain 139 area within $1 \mathrm{~km}$ of the river channel and allocated pathways into one of four classes, giving extra 140 weight to pathways connected to larger floodplains (Table 2).

[Table 2 approx. here]

\section{Geospatial Data Processing}

143 Input data for the hydropower dam optimization model were derived in a series of processing steps 144 using ArcGIS and GRASS (Appendix B). A flow-directed river network was produced based on 145 topological data obtained from Weber et al. (2004). Strahler stream order of each segment was 146 then determined and all segments of order 3 or less subsequently removed. We also determined 147 the Shreve order of each segment using the RivEX toolbox for ArcGIS (Hornby 2014).

148 Spatial coordinates and hydropower generation potential of all existing/proposed hydropower 149 dams were taken from the Brazilian Electricity Energy Regulatory Agency database 150 (SIGEL/ANEEL 2016). For several dam complexes sharing a common reservoir, individual dams 151 were merged into a single location and their generation potential added together. The Barrier 152 Analysis Tool (BAT) add-in for ArcGIS (Hornby 2013) was then used to snap dam locations (50m 
153 snapping distance) to the river network and split the network at each dam site. After snapping, a 154 total of 28 existing and 117 proposed dam sites were identified.

155 Reservoir polygons were created using a specially coded Python script for estimating impounded 156 area above dams. Reservoir polygons were then intersected with the river network to determine 157 portions of the river currently impounded by existing dams or would become impounded if 158 proposed dams were built. In cases where no appreciable reservoir was produced, a dummy 159 segment (length $0 \mathrm{~m}$ ) was inserted into the river network just upstream of the dam (for delineating 160 the terminal segment of a river pathway). The final river network was composed of 13,246 161 confluence and reservoir bounded river segments (including dummy segments).

162 Floodplains were mapped using Landsat 8 OLI imagery. A $1 \mathrm{~km}$ lateral buffer was placed around 163 each river segment to obtain the area of nearby floodplain. Finally, a specially coded C++ routine 164 was used to extract all existing/potential river pathways $(n=6021)$ within the river network.

Hydropower Dam Optimization Model

166 To strategically locate and remove hydropower dams, we develop a spatial optimization model to 167 maximize mean weighted migratory fish species richness within a planning region subject to 168 targets on hydropower generation potential and number of dam removals. We assume that the river 169 network is composed of a set of confluence and reservoir bounded river segments. Species richness 170 in non-impounded river segments is determined based on river pathway length, with longer 171 pathways supporting higher richness. Pathways and their constituent river segments are given

172 proportionally higher weight depending on the amount of accessible floodplain (a proxy for fish 173 abundance). Weightings are also given to river segments based on Shreve stream order. 
175 To develop a mathematical formulation of our hydropower dam location/removal model, we use

176 the notation provided in Table 3 and the following decision variables.

$177 \quad x_{j}= \begin{cases}1 & \text { if hydrowpower dam } j \text { is present } \\ 0 & \text { otherwise }\end{cases}$

$178 y_{f}= \begin{cases}1 & \text { if pathway } f \text { is barrier-free } \\ 0 & \text { otherwise }\end{cases}$

$179 z_{s \ell k}=\left\{\begin{array}{l}1 \text { if segment } s \text { is assigned to a barrier-free pathway of size class } \ell \\ \text { and floodplain class } k \\ 0 \text { otherwise }\end{array}\right.$

180 Variables $z_{s \ell k}$ perhaps require a bit of further explanation. In general, river segments can 181 potentially lie along multiple barrier-free pathways of varying size and floodplain class. As an 182 example, consider the pathways $9 \rightarrow 5$ and $11 \rightarrow 5$ shown in Figure 2, with pathway $9 \rightarrow 5$ forming a 183 subpath of $11 \rightarrow 5$. If dam $\mathrm{C}$ were constructed, then segments 5 and 9 would necessarily be part of 184 the pathway $9 \rightarrow 5$, since pathway $11 \rightarrow 5$ would not be barrier-free. If dam $C$ were not constructed, 185 on the other hand, then pathways $9 \rightarrow 5$ and $11 \rightarrow 5$ would both be barrier-free at the same time. 186 Logically, segments 5 and 9 should form part of the longer pathway $11 \rightarrow 5$. However, as the 187 optimization model needs to evaluate all feasible pathways a choice must, in fact, be made in the 188 event dam $C$ is not built: "assign" segments 5 and 9 to pathway $11 \rightarrow 5$ or to pathway $9 \rightarrow 5$ ?

189 Variables $z_{s \ell k}$ help to keep track of which pathway each segment is ultimately assigned to. 190 Additional constraints within the model (discussed below) ensure every segment is assigned to one 191 and only one pathway, thus preventing double counting (e.g., segments 5 and 9 being 192 simultaneously assigned to pathways $9 \rightarrow 5$ and $11 \rightarrow 5$ ).

193 With this in place, a mixed integer linear programing formulation of our model is then given as 194 follows. 


$$
\max \frac{1}{V} \sum_{s \in S} \sum_{\ell \in L} \sum_{k \in K} v_{s} w_{k} R_{\ell} z_{s \ell k}
$$

s.t.

$$
\begin{array}{ll}
\sum_{j \in J} h_{j} x_{j} \geq \theta H^{\prime} & \\
\sum_{j \in J^{\prime}} x_{j} \geq n^{\prime}-m & \\
x_{j}+x_{t} \leq 1 & \forall j \in J, t \in E_{j} \\
y_{f}+x_{j} \leq 1 & \forall f \in F, j \in B_{f} \\
z_{s \ell k} \leq \sum_{f \in P_{s \ell k}} y_{f} & \forall s \in S, \ell \in L, k \in K \\
\sum_{\ell \in L} \sum_{k \in K} z_{s \ell k} \leq 1 & \forall j \in J \\
x_{j} \in\{0,1\} & \forall f \in F \\
y_{f} \geq 0 & \forall s \in S, \ell \in L, k \in K \\
z_{s \ell k} \geq 0 &
\end{array}
$$

195 The objective (1) maximizes mean migratory fish species richness, weighted by access to

196 floodplain areas, within the river network. This is found by summing across all segments $(s)$,

197 pathway size classes $(\ell)$, and floodplain classes $(k)$ the richness of each pathway $\left(R_{\ell}\right)$, weighted 198 by effective abundance $\left(w_{k}\right)$ and segment size $\left(v_{s}\right)$, and then dividing by total network size $(V)$.

199 Note that in our case study, segment and total network size are measured as order-weighted length $200(\mathrm{~km})$, however, in other situations size could be measured as wetted area $\left(\mathrm{km}^{2}\right)$ or other some other 201 suitable metric. Constraint (2) requires total hydropower potential to be greater than or equal to 202 some multiple $\theta \geq 0$ of current potential $H^{\prime}$. Constraint (3) specifies that no more than $m$ dams 
can be removed among the $n^{\prime}$ existing dams. Given the availability of data on dam removal costs, constraint (3) could just as easily be replaced with the constraint:

$$
\sum_{j \in J^{\prime}} c_{j}\left(1-x_{j}\right) \leq b
$$

205

where $c_{j}$ is the overall cost to remove dam $j$ (including costs associated with feasibility studies, technical planning, demolition, sediment removal, post-removal management, and possibly compensation to dam operators for lost revenue), and $b$ is the available budget for dam removal.

To continue, constraints (4) prevent the nonsensical placement of dams within the "exclusion zone" of any dam site $j$. The exclusion zone for dam site $j\left(E_{j}\right)$ includes all upstream locations that would be completely submerged (within a reservoir) or whose hydropower potential would be excessively reduced (as a result of backwater effects) due to the construction of dam $j$. More specifically, if dam $j$ is present $\left(x_{j}=1\right)$, then no dams within its exclusion zone can be present $\left(x_{t}=0, \forall t \in E_{j}\right)$ or if a dam is present in the exclusion zone of $j\left(\exists t \in E_{j} \mid x_{t}=1\right)$, then dam $j$ cannot be present $\left(x_{j}=0\right)$. Inequalities (5) state that pathway $f$ can be "active" (i.e., designated barrier-free) if and only if no dam is sited along the length of $f\left(x_{j}=0, \forall j \in B_{f}\right)$. Constraint set (6) stipulates that segment $s$ can only be assigned to a pathway of size class $\ell$ and floodplain class $k\left(z_{s \ell k}=1\right)$ if it lies within at least one active pathway of size class $\ell$ and floodplain class $k(\exists f \in$ $\left.P_{s \ell k} \mid y_{f}=1\right)$. Inequalities (7) further require that segment $s$ can be assigned to at most one pathway of any size and floodplain class. Finally, constraints (8) place binary restrictions on the $x_{j}$ dam siting variables, while constraints (9)-(10) require variables $y_{f}$ and $z_{s \ell k}$ to be non-negative. Note that due to the structure of the model, variables $y_{f}$ and $z_{s \ell k}$ are guaranteed to take on binary values. 
222 We point out that our use of river pathways to characterize river connectivity based on free-flowing 223 river length differs distinctly from modeling frameworks described previously in the literature.

224 Existing barrier prioritization models are typically designed either to promote diadromous 225 dispersal by enhancing connectivity between the river mouth and areas of river habitats located upstream of barriers (Kuby et al. 2005; O’Hanley and Tomberlin 2005; Zheng et al. 2009; Neeson et al. 2015; Roy et al. 2018) or promote undirected potadromous dispersal (including internal updown movements and movements between confluent parts of a river) by enhancing connectivity between each and every river habitat area (O’Hanley et al. 2013; King et al. 2017; Erős et al. 2018; Neeson et al. 2018).

Structurally, our proposed model is most closely related to O'Hanley (2011), which presents a 232 formulation for maximizing the largest contiguous section of river unimpeded by dispersal barriers. The O'Hanley (2011) model includes variables and constraints, akin to pathway variables $y_{f}$ and pathway activity constraints (5) described herein, for determining whether two river segments are connected by a barrier-free path and similarly assumes that barriers are completely impassable to fish.

237 We further observe that our model can be viewed more generally as a multi-objective problem 238 involving the maximization of mean weighted migratory fish species richness $\left(\max Z_{1}=\right.$ $\left.239 V^{-1} \sum_{s \in S} \sum_{\ell \in L} \sum_{k \in K} v_{s} w_{k} R_{\ell} z_{s \ell k}\right)$, maximization of hydropower generation potential $\left(\max Z_{2}=\right.$ $240 \sum_{j \in J} h_{j} x_{j}$ ), and minimization of the number of dam removals ( $\min Z_{3}=n^{\prime}-\sum_{j \in J^{\prime}} x_{j}$ ). The latter 241 two objectives are incorporated as constraints in the model, as opposed to the common approach 242 of combining all three into a single weighted objective function (max $\alpha_{1} Z_{1}+\alpha_{2} Z_{2}+\alpha_{3} Z_{3}$, with $243 \alpha_{1}, \alpha_{2} \geq 0$ and $\alpha_{3} \leq 0$ being the weights for objectives $Z_{1}, Z_{2}$, and $Z_{3}$, respectively). To assess 244 tradeoffs among objectives, one can systematically vary minimum hydropower requirements $(\theta)$ 
245 and the maximum number of barrier removals $\left(m^{\prime}\right)$, in order to produce efficient frontiers (i.e.,

246 Pareto curves) of mean weighted species richness versus hydropower potential given a specified

247 number of barrier removals. This approach is more formally known as the $\varepsilon$-constraint method for 248 solving multi-objective problems (Cohon 1978).

249 We implemented our model in the OPL modeling language using CPLEX studio version 12.7.1 250 (IBM 2017). CPLEX is a state-of-the-art commercial software package that employs branch-and251 cut methods to solve mixed integer linear programs (MILPs). All experiments were performed on 252 the same dual-core Lenovo ThinkPad T470 laptop (Intel i7-7600U processor, 2.8GHz per chip) 253 with 32 GB of RAM. Solution times varied from under 1 second to 6.5 minutes, which is 254 remarkable given the large size of the model, which includes 165,118 variables (145 binary) and 255203,132 constraints.

256 Results

257 A range of tradeoffs exist between mean weighted species richness and hydropower generation 258 potential in the São Francisco for different numbers of dam removals (Figure 3). To structure our 259 analysis, we focus on seven selected hydropower development scenarios: 1) a pre-dam baseline in 260 which the river basin is assumed to be in a fully natural state (Baseline); 2) the current situation 261 given existing dams (Current); 3) an ideal scenario in which dam locations are optimized to achieve 262 current generation potential (Ideal); 4) removal of up to one existing dam combined with 263 optimizing the siting of new dams to compensate for lost hydropower (Offset); 5) a 20\% increase 264 in generation potential assuming the fewest number of new dam sites are selected (Future A); 6) a $26520 \%$ increase in generation potential assuming new dam sites are optimized and no existing dams 266 are removed (Future B); and 7) a 20\% increase in generation potential assuming new dam sites are 267 optimized and up to one existing dam can be removed (Future C). Note that comparisons between 
scenarios are based largely on mean weighted migratory fish richness. Weighted richness (range 2-21 species) accounts for the importance of floodplain access and is, therefore, generally much higher than unweighted richness (range 2-12 species).

[Figure 3 approx. here]

It is clear that hydropower development in the São Francisco has detrimentally impacted fish biodiversity. Weighted richness has been reduced by $51 \%$ (from 20.2 species to 9.9 species) compared to a pre-dam baseline (Current versus Baseline, Figure 3). Had dam sites been optimized from the start, average weighted species richness would be $63 \%$ higher (+6.2 species) relative to the current value (Ideal, Figure 4a). If one dam can be removed while ensuring hydropower potential is offset by the optimal siting of new dams, then weighted richness could increase $25 \%$ (+2.4 species) above the current average (Offset, Figure 4a).

Moving forward, optimizing dam placement and removal could provide substantial benefits in terms of increased hydropower and foregone biodiversity loss. Increasing hydropower potential by $20 \%$ would cause weighted richness to decrease a further $10 \%$ (-1 species) if dam locations decisions are not optimized (Future A, Figure 4a). When dam placements are optimized, however, only a $1 \%$ reduction ( -0.1 species) occurs (Future B, Figure $4 a)$. In relative terms, this represents an $89 \%$ reduction in richness loss. If up to one existing hydropower dam can be removed at the same time (the Sobradinho dam, Figure 1), then a $20 \%$ increase in hydropower could be achieved while simultaneously increasing weighted richness by 19\% (Future C, Figure 4a).

[Figure 4 approx. here]

A more in-depth analysis of the results reveals two key insights. The first is that building many small and medium megawatt dams in the upper reaches of the basin would yield substantially 
290 better biodiversity outcomes than building a few large megawatt dams along the São Francisco

291 River or its main tributaries. The Offset scenario, for example, achieves higher fish richness

292 compared to the Current scenario by removing one very large dam situated on the main stem (the

293 1005MW Sobradinho dam) and replacing it with 35 smaller dams (mean 30MW) located mainly

294 on minor tributaries (Figure 5b). Similarly, optimized solutions Future B and Future C, which both

295 produce higher richness compared to non-optimized solution Future A, recommend siting around

29612 times the number of new dams as Future A (107-109 versus 9, Figure 4b), with average

297 hydropower per new dam around a tenth (20-29MW versus $240 \mathrm{MW})$. For Future B, no new dams

298 are located on the main stem below Três Marias (Figure 5d). For Future C, only two new dams are

299 found along the main stem below Três Marias (Figure 5e) - one in the lower part of the basin

300 below the Sobradinho, the other a short distance downstream from the Três Marias. Future A, in

301 contrast, locates four dams on the main stem and all but one of the five other dams near the

302 confluences of major tributaries (Figure 5c). Intuitively, the siting pattern for optimized solutions

303 makes sense. Species richness losses for optimized solutions tend to be localized in low-order

304 tributaries, while access to floodplains, which is mostly found along high-order channels, is

305 maintained.

[Figure 5 approx. here]

307 A second key insight is that even limited dam removal has the potential to significantly enhance

308 fish biodiversity. The Offset and Future C scenarios both produce a significant increase in fish

309 richness (19-25\%) with removal of a single dam. These scenarios are not unique in this regard,

310 however. The curve for weighted richness versus hydropower potential given $\leq 1$ dam removal is

311 near optimal (i.e., almost overlaps the $\leq 28$ dam removal curve) for a $15 \%$ increase in hydropower

312 or higher, while the curve given $\leq 2$ dam removals is near optimal for current levels of hydropower 
313 or higher (Figure 3). What this indicates is that removing just 1-2 dams could return the São

314 Francisco to a near optimal state depending on hydropower requirements.

315 On this last point, while the benefits of dam removal are unequivocal, what is not so clear is the 316 feasibility of implementing any given set of optimized dam removals in light of attendant costs 317 and other considerations. For example, both the Offset and Future C scenarios recommend removal 318 of the $41 \mathrm{~m}$ high, $12.5 \mathrm{~km}$ wide Sobradinho dam. With an installed capacity of $1005 \mathrm{MW}$, the 319 Sobradinho alone accounts for almost $10 \%$ of the São Francisco basin's current hydropower 320 potential. It is hard to imagine any realistic scenario in which such a large dam (both in terms of 321 physical size and amount of hydropower) would be removed anytime soon.

323 In cases where it is impractical to remove specific dams, supplementary optimization runs can be 324 performed to find a range of alternative options. Indeed, a comparison of the first to fourth best 325 alternative solutions given a $0 \%$ or $20 \%$ increase in hydropower and up to one dam removal (Figure 326 6) reveals that the next best alternative yields a similar level of improvement in weighted species 327 richness as the first best alternative (20\% versus $25 \%$ increase in richness given a $0 \%$ increase in 328 hydropower, $17 \%$ versus a $19 \%$ increase in richness given a $20 \%$ increase in hydropower). In both 329 cases, the dam slated for removal is the Três Marias dam. While the Três Marias would certainly 330 be classed as a very large hydropower dam (396MW), it is much older than the Sobradinho. 331 Completed in 1961 primarily for flood control, irrigation, and navigation (Britski et al. 1988), the 332 dam is almost 60 years old. Given that the typical life-span of hydropower dam is 50-100 years 333 (Yüksel 2010), it is not inconceivable to propose removing the Três Marias. What is more, recent 334 droughts have caused major reductions in the dam's reservoir levels and, in turn, effective 
335 hydropower potential. As recently as 2016, reservoir volume of the Três Marias was only at 38\%

336 of capacity at the end of wet season (BHAZ 2016).

337 Discussion

338 Our study testifies to the enormous power of optimization models for improving the efficiency of 339 environmental planning. We find that optimizing the siting of new dams can significantly reduce 340 migratory fish species losses compared to selecting the fewest number of dams. Moreover, when

341 decisions about locating new dams are combined with the option to remove a small number of 342 existing dams, it is possible to create a win-win in which both increased hydropower and increased 343 fish richness are achieved.

344 Previous studies have shown that benefits of optimization are often most pronounced when 345 planning resources are tight (O’Hanley and Tomberlin 2005). Brazil is currently experiencing an 346 economic downturn with negative growth, which has led to substantial cuts in discretionary 347 government spending, including the environment. Moving forward, the use of optimization to 348 guide and efficiently plan hydropower expansion, while limiting impacts on fragile river 349 ecosystems, could prove immensely beneficial to Brazil and other developing nations.

350 In point of fact, features of our model make it well suited for informing efficient hydropower 351 development across the wider tropics and subtropics (e.g., the Amazon, Mekong, equatorial 352 Africa), where the vast majority of hydropower dam building expected to be concentrated in the 353 coming years (Grill et al. 2015; Winemiller et al. 2016). Unlike existing barrier optimization 354 approaches, our model is specifically designed to accommodate the life-cycle patterns common to 355 tropical migratory fish species (i.e., pelagic-broadcast spawners). More importantly, the model is 356 data light - only basic biological information (i.e., estimates of species richness as a function of 357 river length and floodplain size class multipliers) and easy-to-obtain geospatial data (i.e., river 
network, floodplain area, dam location, and reservoir area data) are required. This is a key advantage as developing countries are often hindered by a lack of high quality data, especially detailed biological information (Groves et al. 2002).

We acknowledge that dam removals recommended by our model may not always be practical. For example, given a $0 \%$ or $20 \%$ increase in hydropower and up to one dam removal, the model recommends removing the Sobradinho dam. The Sobradinho is a very large dam that supplies a significant amount of the basin's hydropower, making its removal an impossibility given current political and socioeconomic realities. In cases where practical consideration prohibit the removal of specific dams, our model can nonetheless be used to find next best solutions (Lawler 1972) which target the removal of other, less controversial dams. Alternatively, one could consider making a simple change to the model to allow removal of only certain categories of dams, for instance older and or smaller (low megawatt) hydropower dams.

It is worth mentioning at least four simplifications of our study. First, due to a lack of catchmentwide data regarding fish species endemism, we had no choice but to treat equally sized sections of river with equal floodplain access as fungible. Given species distribution data, a more targeted approach to conservation could be adopted that limits losses for species of conservation concern. Second, we did not consider the potential effects of dams on flow regulation. Consequently, our model likely underestimates reductions in weighted fish richness due to the reduction of floodplain areas (Nestler et al. 2012). Third, our model does not take into account the importance of how different habitat types are spatially distributed. Separation of spawning and rearing grounds by dams and reservoirs can create source-sink dynamics (Godinho and Kynard 2009) and ecological traps (Pelicice and Agostinho 2008). Incorporating additional autecology and spatial information could reduce the risk posed by confining fish populations within short reaches lacking the full 
381 range of critical habitats. Fourth, an interesting modification to our model would be to relax the 382 assumption that dams form total barriers to fish dispersal. For example, reservoirs below critical 383 size thresholds (Pelicice et al. 2015) should permit at least a fraction of embryos/larvae to move 384 and potentially supplement richness downstream, whereas fish passes with even limited 385 effectiveness might enable sufficient numbers of adults to pass small dams and access upstream 386 spawning areas. More realistic modeling of fish dispersal could help to identify better opportunities 387 for locating, removing, or mitigating dams that maximize fish biodiversity.

\section{Acknowledgements and Data}

389 Funding was provided in part by a grant from Fundação de Amparo à Pesquisa de Minas Gerais 390 (FAPEMIG, grant no. APQ 0003-15) and by a British Council, Newton Fund Institutional Links 391 grant (grant no. 20181003). 


\section{References}

BHAZ (2016) Após chegar a 2\% da capacidade, Usina de Três Marias se recupera e alcança 37\% (After reaching 2\% of capacity, Três Marias Plant recovers and reaches 37\%). BHAZ, 05 Sep [Online]. Available at: <https://bhaz.com.br/2016/05/09/apos-chegar-a-2-da-capacidade-usinade-tres-marias-se-recupera-e-alcanca-37> (last accessed 26 Sep 2019).

Britski, H.A., Sato, Y., Rosa, A.B.S. (1988) Manual de identificação de peixes da região de Três Marias, Minas Gerais. Codevasf, Brasilia, Brazil.

Brown, J.J., Limburg, K.E., Waldman, J.R., Stephenson, K., Glenn, E.P., Juanes, F., Jordaan, A. (2013) Fish and hydropower on the U.S. Atlantic coast: Failed fisheries policies from half-way technologies. Conservation Letters 6: 280-286.

Buckup, P.A., Menezes, N.A., Ghazzi, M.S. (2007) Catálogo das espécies de peixes de água doce do Brasil. Museu Nacional, Rio de Janeiro, Brazil.

Carolsfield, J., Harvey, B., Ross, C., Baer, A. (2003) Migratory Fishes of South America: Biology, Fisheries, and Conservation Status. International Bank for Reconstruction and Development/World Bank, Washington, D.C.

Cohon, J.L. (1978) Multiobjective programming and planning. Academic Press, New York.

Dudgeon, D., Arthington, A.H., Gessner, M.O., Kawabata, Z.L., Knowler, D.J., Leveque, C., Naiman, R.J., Prieur-Richard, A.H., Soto, D., Stiassny, M.L.J., Sullivan, C.A. (2006) Freshwater biodiversity: Importance, threats, status and conservation challenges. Biological Reviews 81: 163-182.

Erős, T., O’Hanley, J.R., Czeglédi, I. (2018) A unified model for optimizing riverscape conservation. Journal of Applied Ecology 55(4): 1871-1883. 
414 FAO (2012) Fishery and Aquaculture Country Profiles: The Federative Republic of Brazil. Food 415 and Agriculture Organization of the United States (FAO), FAO Fishery Statistics and 416 Information Unit. Available at: <http://www.fao.org/fishery/facp/BRA/en\#CountrySector$417 \quad$ Statistics> (last accessed 05 Sep 2016).

418 Godinho, A.L., Kynard, B. (2009) Migratory fishes of Brazil: Life history and fish passage needs. $419 \quad$ River Research and Applications 25(6): 702-712.

420 Godinho, A.L., Pompeu, P.S. (2003) A importância dos ribeirões para os peixes de piracema. Pp. 361-372 in: Godinho, H.P., Godinho, A.L. (Eds.) Águas, peixes e pescadores do São Francisco da Minas Gerais. Pontifical Catholic University of Minas Gerais, Belo Horizonte, Brazil. index-based framework for assessing patterns and trends in river fragmentation and flow regulation by global dams at multiple scales. Environmental Research Letters 10: 015001.

Groves, C.R., Jensen, D.B., Valutis, L.L., et al. (2002) Planning for biodiversity conservation: putting conservation science into practice: A seven-step framework for developing regional plans to conserve biological diversity, based upon principles of conservation biology and ecology, is being used extensively by the nature conservancy to identify priority areas for conservation. BioScience 52(6): 499-512.

Hogan, Z.S., Moyle, P.B., May, B., Vander Zanden, M.J., Baird, I.G. (2004) The imperiled giants of the Mekong. American Scientist 92: 228-237.

434 Southampton.

435 Hornby, D. (2014) RivEX version 10.19 [Software]. Available at: <www.rivex.co.uk> (last $436 \quad$ accessed 26 Oct 2017). 
Ioannidou, C., O’Hanley, J.R. (2018) Eco-friendly location of small hydropower. European Journal of Operational Research 264(3): 907-918.

Kemp, P.S., O'Hanley, J.R. 2010. Procedures for evaluating and prioritising the removal of fish passage barriers: A synthesis. Fisheries Management and Ecology 17: 297-322.

King, S., O’Hanley, J.R., Newbold, L., Kemp, P.S., Diebel, M.W. (2017) A toolkit for optimizing barrier mitigation actions. Journal of Applied Ecology 54: 599-611.

Knoppers B., Medeiros P.R.P., Souza W.F.L., Jennerjahn, T. (2006) The São Francisco Estuary, Brazil. The Handbook of Environmental Chemistry 5: 51-70.

Kocovsky, P.M., Ross, R.M., Dropkin, D.S. (2009) Prioritizing removal of dams for passage of diadromous fishes on a major river system. River Research and Applications 25: 107-117.

Kuby, M.J., Fagan, W.F., ReVelle, C.S., Graf, W.L. (2005) A multiobjective optimization model for dam removal: An example of trading off salmon passage with hydropower and water storage in the Willamette basin. Advances in Water Resources 28: 845-855.

Lawler, E.L. (1972) A procedure for computing the $\mathrm{k}$ best solutions to discrete optimization problems and its application to the shortest path problem. Management Science 18(7): 401-405.

Little, P.E. (2014) Megaprojects in Amazonia: A geopolitical and socio-environmental primer. Available at: <http://www.dar.org.pe/archivos/publicacion/145_megaproyectos_ingles_ final.pdf> (last accessed 05 Sep 2016).

McLaughlin, R.L., Smyth, E.R.B., Castro-Santos, T., Jones, M.L., Koops, M.A., Pratt, T.C., Vélez-Espino, L.A. (2013) Unintended consequences and tradeoffs of fish passage. Fish and Fisheries 14: 580-604. 
Neeson, T.M., Ferris, M.C., Diebel, M.W., Doran, P.J., O'Hanley, J.R., McIntyre, P.B. (2015) Enhancing ecosystem restoration efficiency through spatial and temporal coordination. Proceedings of the National Academy of Sciences, USA 112(19): 6236-6241.

Neeson, T.M., Moody, A.T., O’Hanley, J.R., Diebel, M.W., Doran, P.J., Ferris, M.C., Colling, T., McIntyre, P.B. (2018) Aging infrastructure creates opportunities for cost-efficient restoration of aquatic ecosystem connectivity. Ecological Applications 28(6): 1494-1502.

Nestler, J.M., Pompeu, P.S., Smith, D.L., Goodwin, R.A., Silva, L., Baigun, C.R.M., Oldani, N.O. (2012) The river machine: A template for fish movement and habitat, fluvial geomorphology, fluid dynamics, and biogeochemical cycling. Rivers Research and Applications 28: 490-503.

Noonan, M.J., Grant, J.W.A., Jackson, C.D. (2012) A quantitative assessment of fish passage efficiency. Fish and Fisheries 13: 450-464.

O'Hanley, J.R. (2011) Open rivers: barrier removal planning and the restoration of free-flowing rivers. Journal of Environmental Management 92: 3112-3120.

O'Hanley, J.R., Tomberlin, D. (2005) Optimizing the removal of small fish passage barriers. Environmental Modeling and Assessment 10: 85-98.

O’Hanley, J.R., Wright, J., Diebel, M., Fedora, M.A., Soucy, C.L. (2013) Restoring stream habitat connectivity: A proposed method for prioritizing the removal of resident fish passage barriers. Journal of Environmental Management 125: 19-27.

Owen, D., Apse, C. (2015) Trading Dams. UC Davis Law Review 48: 1043. Available at: <https://repository.uchastings.edu/faculty_scholarship/1244> (last accessed 23 Oct 2017).

Pelicice, F.M., Agostinho, A.A. (2008) Fish passage facilities as Ecological traps in large neotropical rivers. Conservation Biology 22: 180-188. 
Pelicice, F.M., Pompeu, P.S., Agostinho A.A. (2015) Large reservoirs as ecological barriers to downstream movements of Neotropical migratory fish. Fish and Fisheries 16: 697-715.

Pompeu, P.S., Agostinho, A.A., Pelicice, F.M. (2012) Existing and future challenges: The concept of successful fish passage in South America. Rivers Research and Applications 28: 504-512.

Roy, S.G., Uchida, E., de Souza, S.P., et al. (2018) A multiscale approach to balance trade-offs among dam infrastructure, river restoration, and cost. Proceedings of the National Academy of Sciences, USA 115(47): 12069-12074.

Sato Y., Godinho, H.P. (2004) Migratory fishes of the São Francisco River. Pp. 195-232 in: Carolsfield, J., Harvey, B., Ross, C., Baer, A. (Eds.) Migratory fishes of South America: Biology, fisheries, and conservation status. World Fisheries Trust/Word Bank/International Development Research Centre, Washington, DC.

Segurado, P., Branco, P., Ferreira, M.T. (2013) Prioritizing restoration of structural connectivity in rivers: A graph based approach. Landscape Ecology 28: 1231-1238.

SIGEL/ANEEL (2016) Sistema de Informações Georreferenciadas do Setor Elétrico. Agência Nacional de Energia Elétrica. Available at: <http://sigel.aneel.gov.br/sigel.html> (last accessed 05 Sep 2016).

Strayer, D.L., Dudgeon, D. (2010) Freshwater biodiversity conservation: Recent progress and future challenges. Journal of the North American Benthological Society 29: 344-358.

Tan, A., Sheng, W. (2004) Distribution of river lengths and the total length of rivers. Mathematical Spectrum 36(3): 52-54.

Watkin, L., Kemp, P.S., Williams, I.D., Harwood, I.A. (2012) Managing sustainable development conflicts: The impact of stakeholders in small-scale hydropower schemes. Environmental Management 49: 1208-1223. 
503 Weber, E., Hasenack, H., Ferreira, C.J.S. (2004) Adaptação do modelo digital de elevação do 504 SRTM para o sistema de referência oficial brasileiro e recorte por unidade da federação. Porto 505 Alegre, UFRGS Centro de Ecologia. Available at: <http://www.ecologia.ufrgs.br/ labgeo> (last 506 accessed 11 Oct 2017).

507 Welcomme, R.L. (1990) Status of fisheries in South American Rivers. Interciencia 15: 337-345.

508 Winemiller, K.O., McIntyre, P.B., Castello, L. et al. (2016) Balancing hydropower and 509 biodiversity in the Amazon, Congo, and Mekong. Science 351: 128-129.

510 WWF (2014) WWF living planet report 2014. World Wildlife Fund (WWF). Available at: $511<$ <ttps://www.wwf.or.jp/activities/data/WWF_LPR_2014.pdf> (last accessed 29 Sep 2017).

512 Yüksel, I. (2010) Hydropower for sustainable water and energy development. Renewable and $513 \quad$ Sustainable Energy Reviews 14(1): 462-469.

514 Zambaldi, L., Pompeu, P.S. (Under review) Evaluation of river fragmentation and implications for 515 the conservation of migratory fish in south eastern Brazil. Journal of Applied Ichthyology.

516 Zheng, P.Q., Hobbs, B.F., Koonce, J.F. (2009) Optimizing multiple dam removals under multiple 517 objectives: linking tributary habitat and the Lake Erie ecosystem. Water Resources Research $518 \quad 45:$ W12417.

519 Ziv, G., Baran, E., Nam, S., Rodríguez-Iturbe, I., Levin, S.A. (2012) Trading-off fish biodiversity, 520 food security, and hydropower in the Mekong River Basin. Proceedings of the National $521 \quad$ Academy of Sciences, USA 109: 5609-5614. 
522 Table 1. Migratory fish species richness for different river pathway size classes.

\begin{tabular}{llc}
\hline Pathway Size Class & Length $(\mathrm{km})$ & No. of Species \\
\hline Small & $<50$ & 2 \\
Medium & $50-100$ & 6 \\
Large & $\geq 100$ & 12
\end{tabular}

523

524

525 Table 2. Migratory fish species abundance weightings based on access to different floodplain area

526 classes.

\begin{tabular}{llc}
\hline Floodplain Size Class & Area $\left(\mathrm{km}^{2}\right)$ & Weighting \\
\hline None & 0 & 1.00 \\
Small & $<175$ & 1.10 \\
Medium & $175-550$ & 1.25 \\
Large & $\geq 550$ & 1.75
\end{tabular}

527 


\begin{tabular}{|c|c|}
\hline Set/Parameter & Definition \\
\hline$S$ & Set of river segments within the river network, indexed by $s$ \\
\hline$F$ & Set of river pathways, indexed by $f$ \\
\hline$L$ & Set of pathway size classes, indexed by $\ell$ \\
\hline$K$ & Set of floodplain size classes, indexed by $k$ \\
\hline$P_{s \ell k}$ & Subset of pathways of size class $\ell$ and floodplain class $k$ containing segment $s$ \\
\hline$J$ & Set of existing and candidate hydropower dam sites, indexed by $j$ \\
\hline$J^{\prime}$ & Subset of existing dam sites \\
\hline$B_{f}$ & Subset of intervening dam sites along pathway $f$ \\
\hline$E_{j}$ & $\begin{array}{l}\text { Subset of dam sites (possibly empty) in the upstream exclusion zone of site } j \text {, } \\
\text { indexed by } t\end{array}$ \\
\hline$v_{S}$ & $\begin{array}{l}\text { Size (order-weighted length) of river segment } s \text {, where } v_{s}=d_{s} o_{s} \text {, with } d_{s} \\
\text { being the length }(\mathrm{km}) \text { and } o_{s} \text { the Shreve order of segment } s\end{array}$ \\
\hline$V$ & Total size of the river network $(\mathrm{km})$, where $V=\sum_{s \in S} v_{S}$ \\
\hline$R_{\ell}$ & $\begin{array}{l}\text { Number of migratory fish species in pathway size class } \ell \text { (range } 2-12 \text {, see } \\
\text { Table } 1 \text { ) }\end{array}$ \\
\hline$w_{k}$ & $\begin{array}{l}\text { Migratory fish abundance weight for pathways of floodplain size class } k \\
\text { (range } 1-1.75, \text { see Table 2) }\end{array}$ \\
\hline$n^{\prime}$ & Number of existing hydropower dams, such that $n^{\prime}=\left|J^{\prime}\right|$ \\
\hline$h_{j}$ & Hydropower generation potential of dam site $j(\mathrm{MW})$ \\
\hline$H^{\prime}$ & Total hydropower potential of all existing dams (MW), where $H^{\prime}=\sum_{j \in J^{\prime}} h_{j}$ \\
\hline
\end{tabular}


Parameter for controlling required hydropower potential

$m$

Upper limit on the number of existing dams that can be removed 
Figure 1. The São Francisco River basin showing existing and potential hydropower sites.

534 Figure 2. Example river network with dams shown as small lettered rectangles. Dams A and B are 535 existing structures (solid lines), dam $\mathrm{C}$ is a proposed structure (dashed lines). Blue shaded areas 536 above each dam depict reservoirs (solid lines for existing, dashed lines for proposed). The river 537 network is split into a total of 16 river segments (numbered 1 to 16 ) based on confluence and 538 reservoir bounding points. All four possible pathway types are shown (dashed orange curves). 539 Starting/ending segments 16 and 1 form a "terminus-to-mouth" pathway (denoted 16 $\rightarrow 1), 11 \rightarrow 5$ 540 is a "terminus-to-above reservoir" pathway, $2 \rightarrow 1$ is a "below dam-to-mouth" pathway, and $6 \rightarrow 5$

541 is a "below dam-to-above reservoir" pathway. If dam C were installed, then pathway $11 \rightarrow 5$ would 542 be split into two new pathways $11 \rightarrow 11$ and $9 \rightarrow 5$. If dam B were removed, then pathways $8 \rightarrow 8$ and $543 \quad 6 \rightarrow 5$ would be replaced by a new pathway $8 \rightarrow 5$.

Figure 3. Efficient frontiers of mean weighted migratory fish species richness versus hydropower 546 generation given removal of $0, \leq 1, \leq 2$, and $\leq 28$ (all) existing dams. A hydropower multiplier $\theta$ 547 equal to 1 corresponds to current generation potential. Values of $\theta$ greater than (less than) 1 548 corresponds to increased (reduced) generation potential. Scenarios Baseline, Current, Ideal, Offset, 549 Future B, and Future C represent specific solutions along the different efficient frontiers with the 550 curve for $\leq 28$ removals representing the theoretical maximum for mean weighted richness that 551 could be achieved for any desired level of hydropower potential. Scenario Future A falls below 552 the efficient frontier since dam locations are not optimized for this scenario. 
553 Figure 4. Percent change in mean weighted migratory fish species richness relative to current (a)

554 and number of existing/new dams (b) for select dam development scenarios.

556 Figure 5. Spatial layout of existing and new dam locations and resulting mean weighted migratory 557 fish species richness of river pathways in the São Francisco basin for the scenarios Current (a), 558 Offset (b), Future A (c), Future B (d), and Future C (e).

559

560 Figure 6. Percent change in mean weighted migratory fish species richness relative to current for 561 the first to fourth best optimal solutions given a $0 \%$ increase (a) or $20 \%$ increase (b) in hydropower 562 generation potential and up to one barrier removal. Given a $0 \%$ increase in hydropower, the first 563 best solution corresponds to the Offset scenario. Given a $20 \%$ increase in hydropower, the first 564 best solution corresponds to the Future C scenario. For each hydropower target, second to fourth 565 best solutions were found by iteratively adding additional constraints that prevented the 566 optimization model from finding the previous solution. 


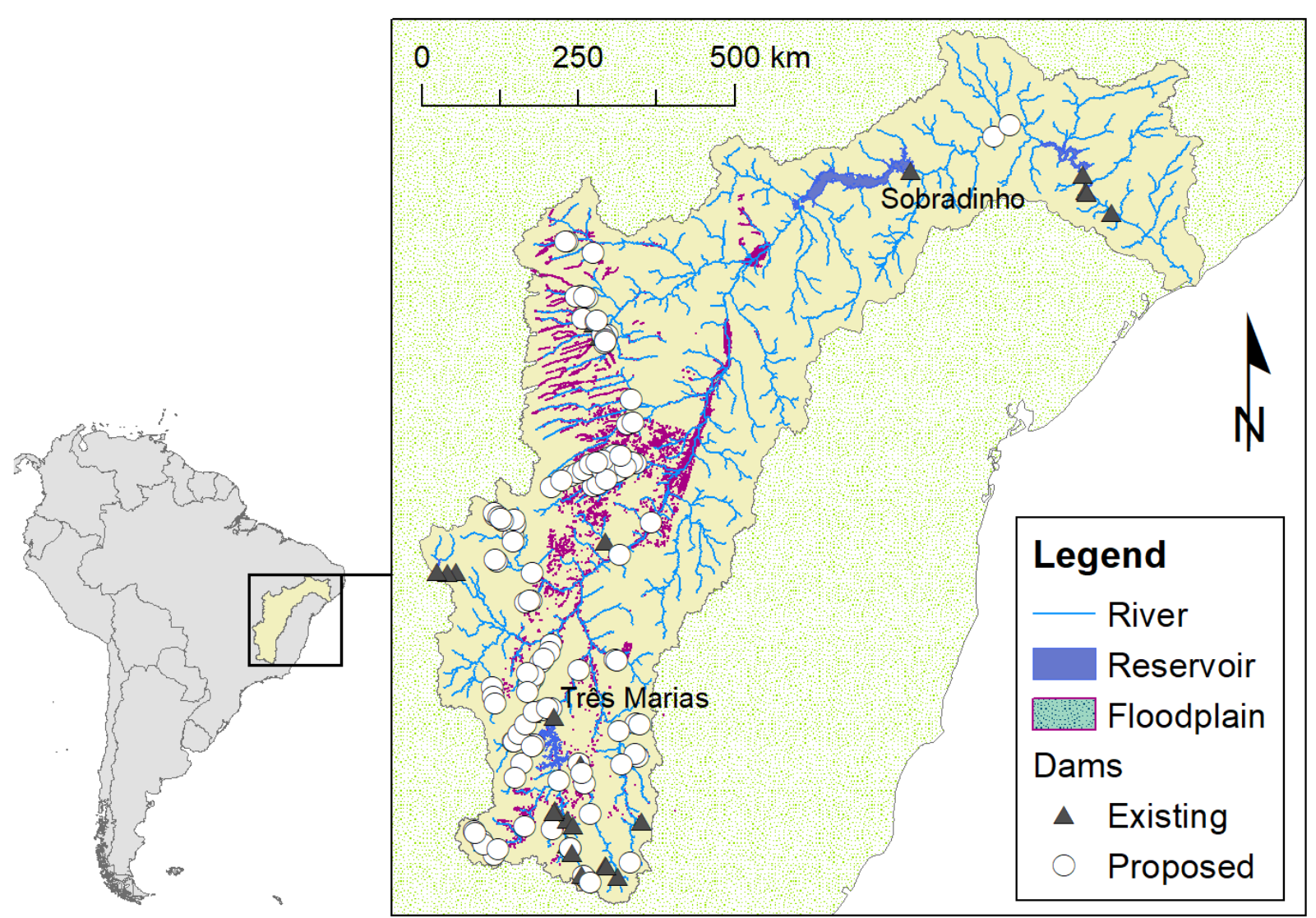

569 
570 [Figure 2]

571

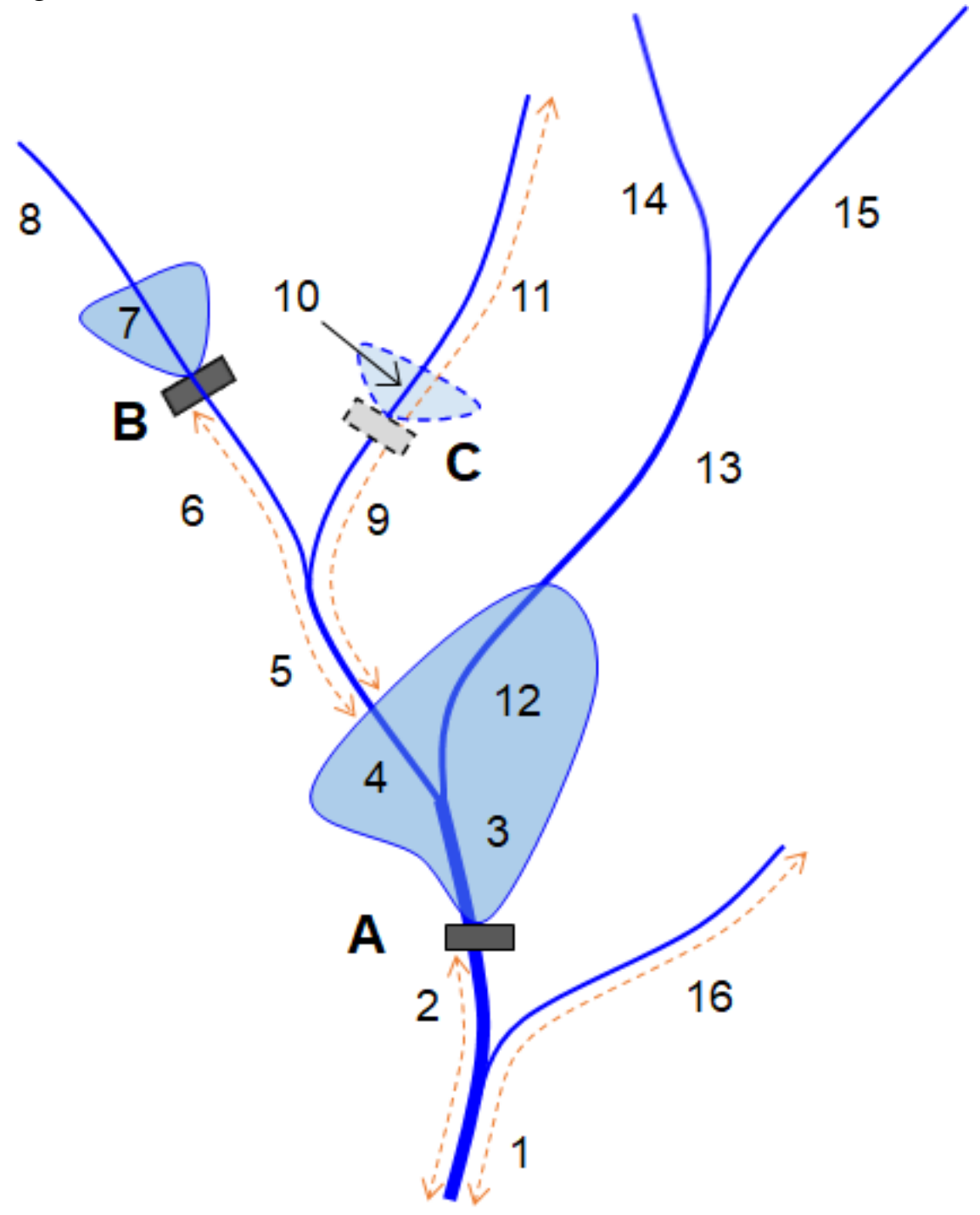




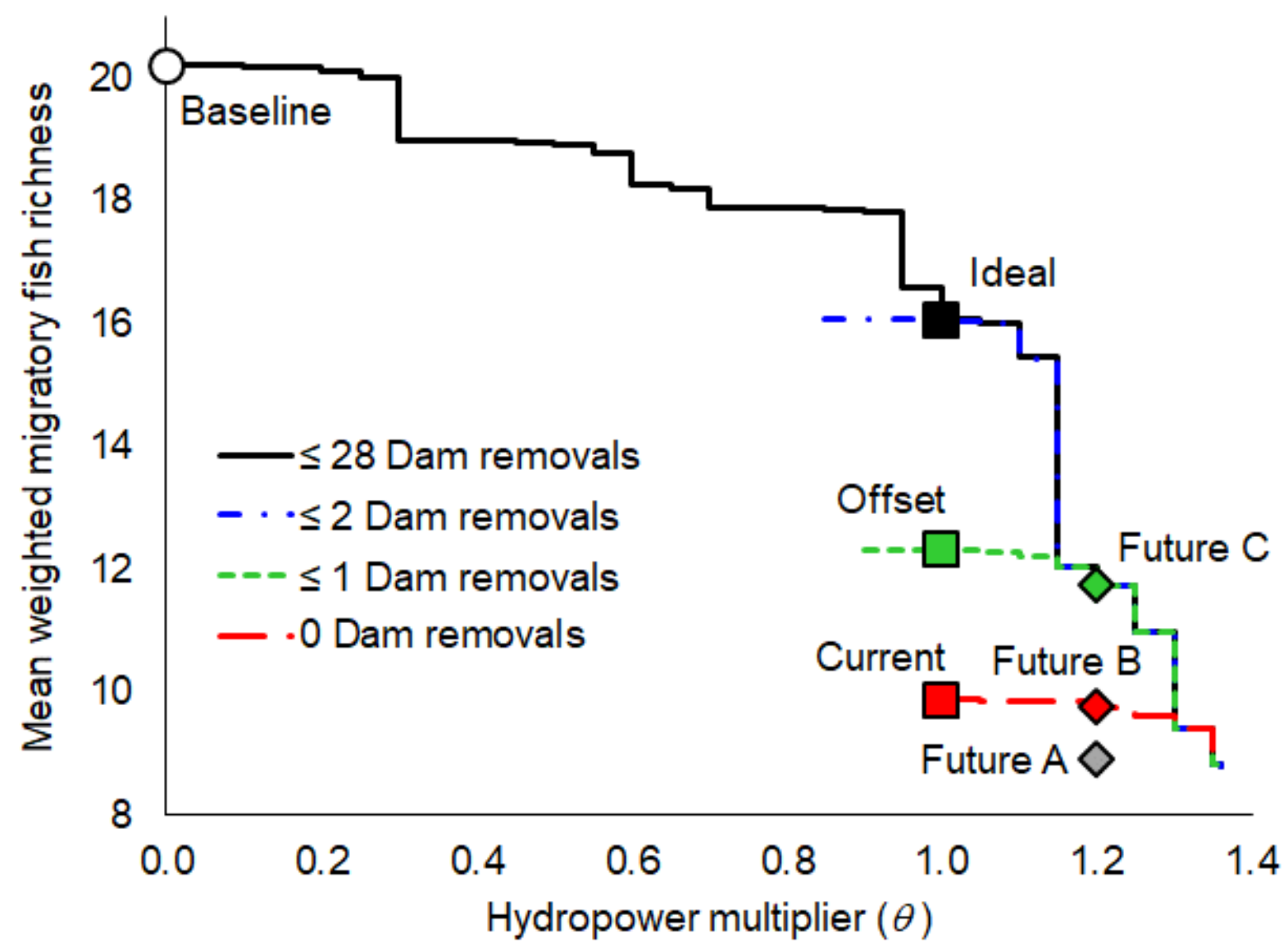


574 [Figure 4a]

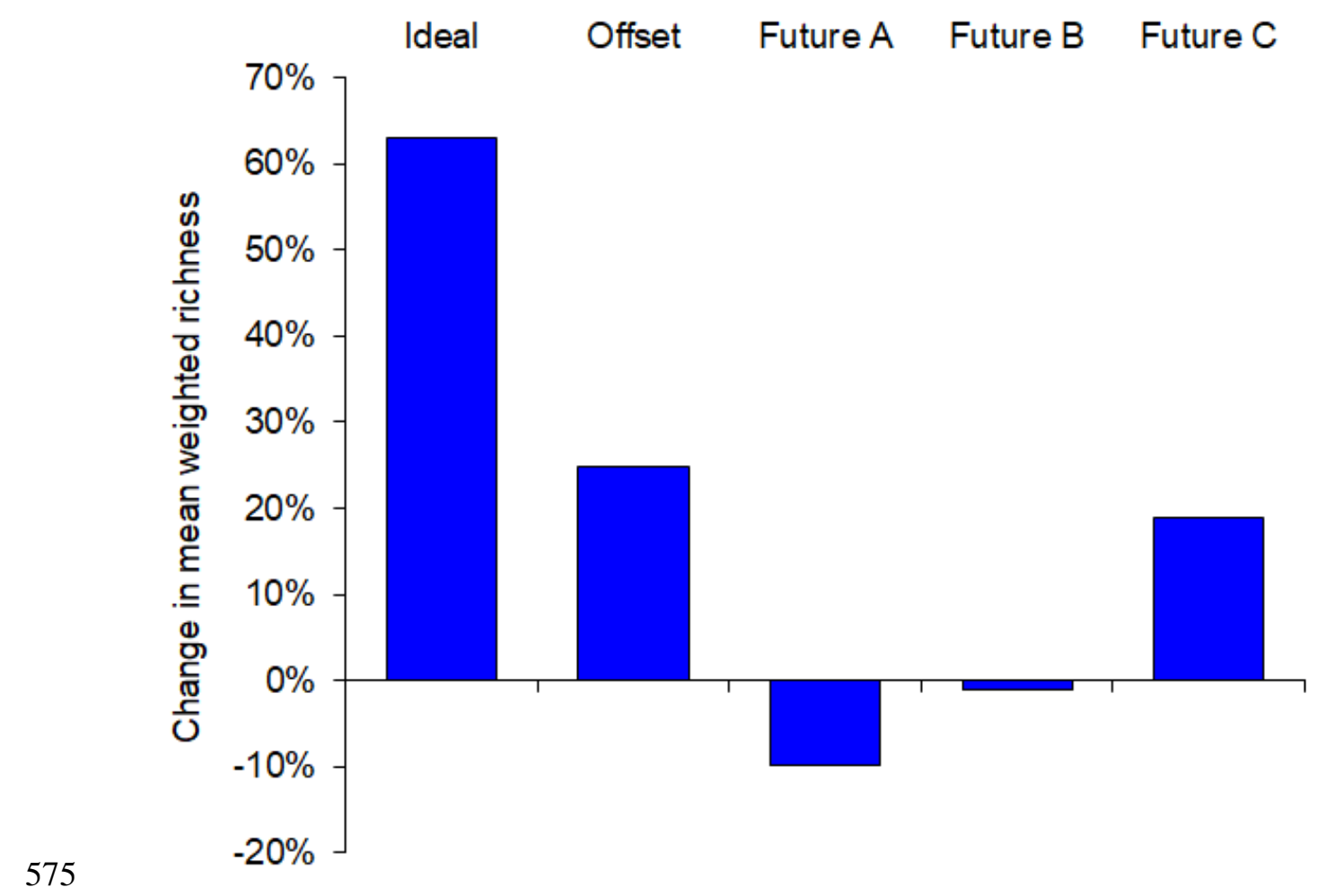

576 [Figure 4b]

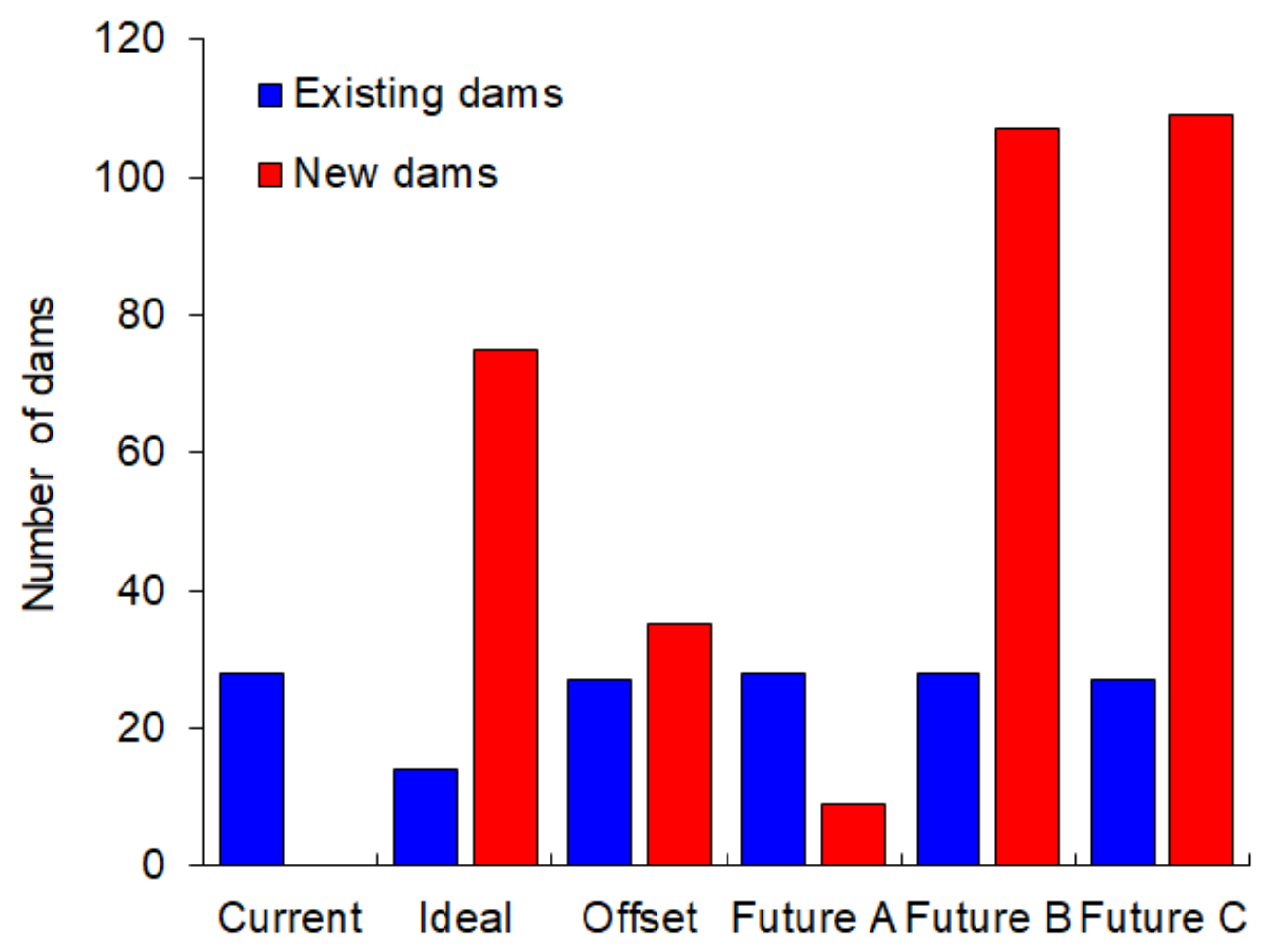




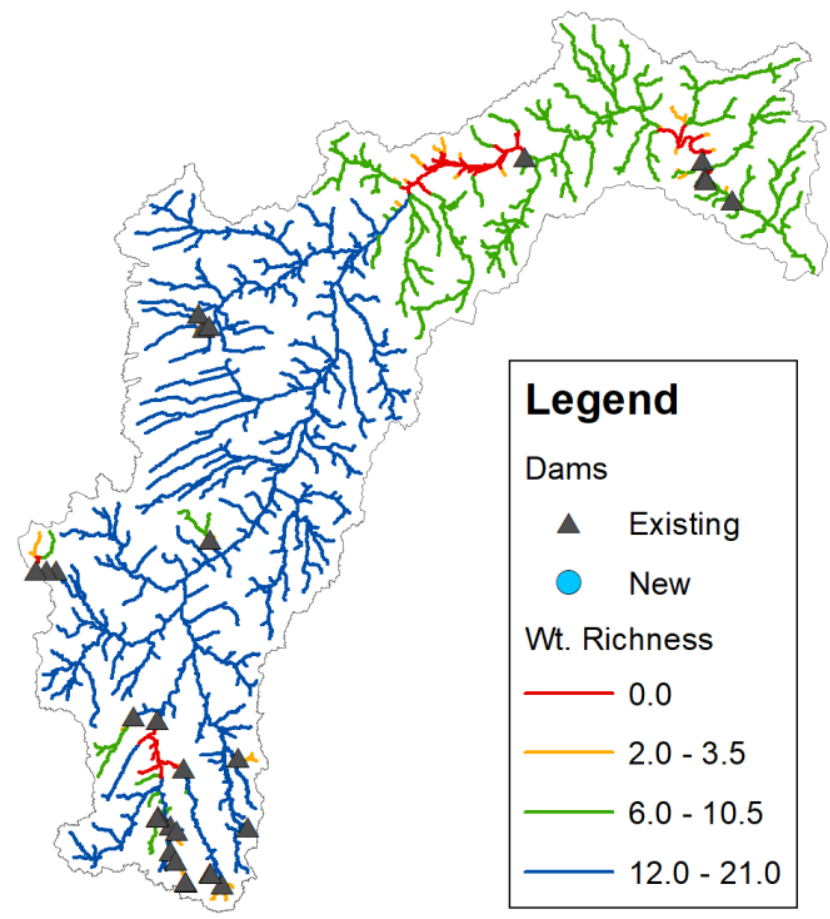

579

580 [Figure 5b]

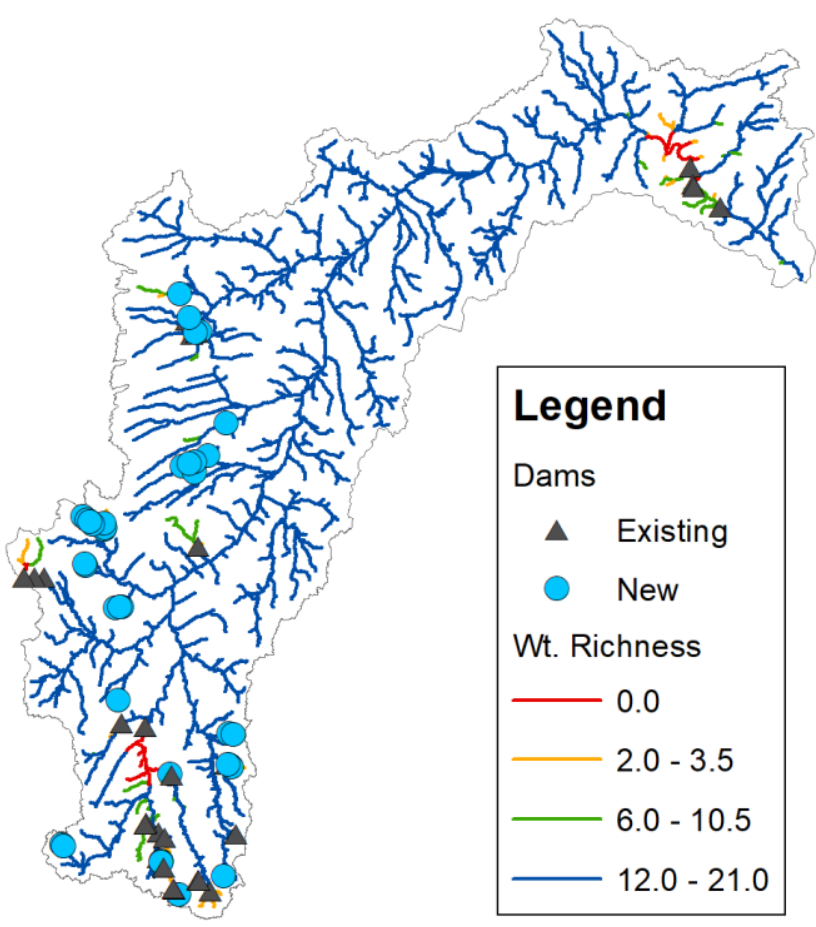




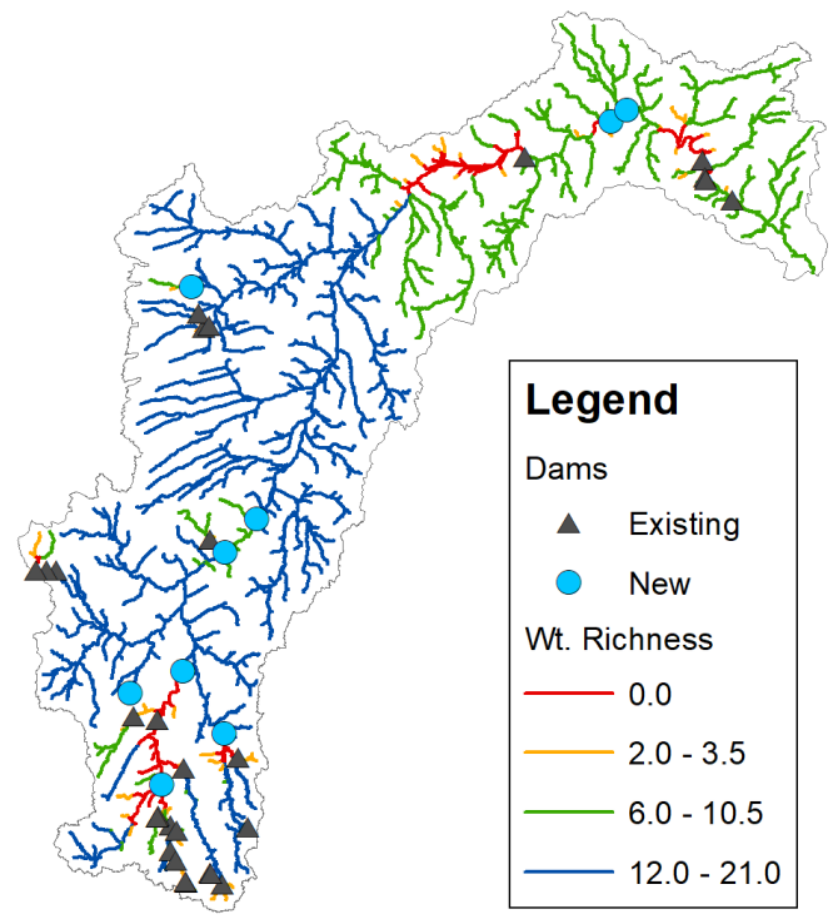

583

584 [Figure 5d]

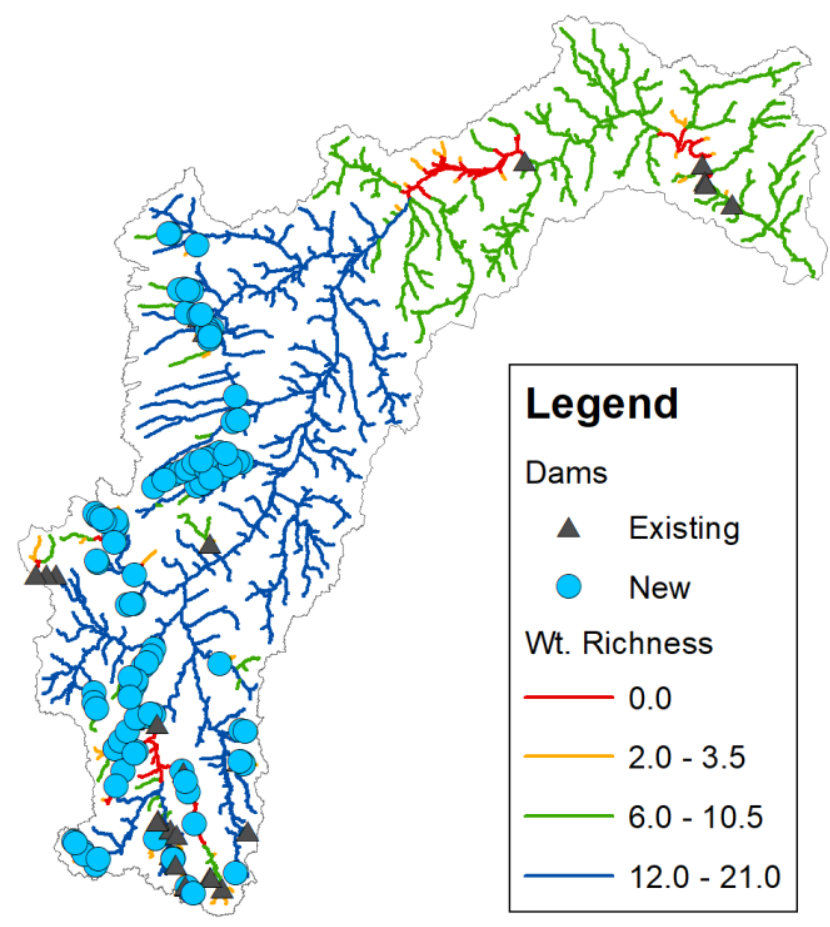


[Figure 5e]

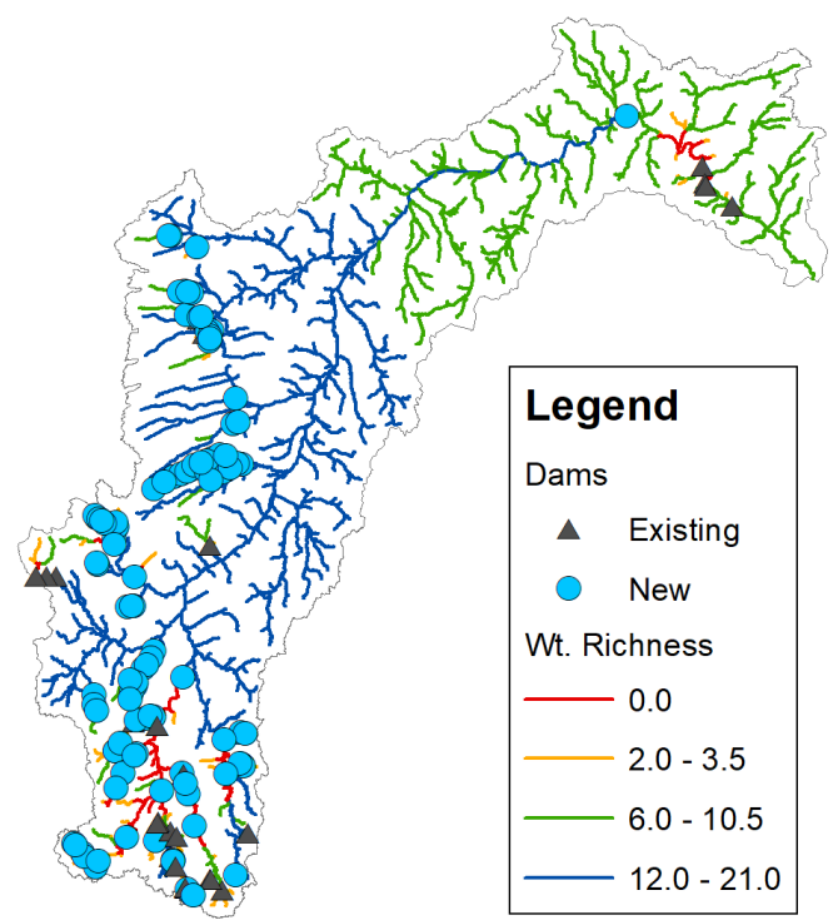

587

588 


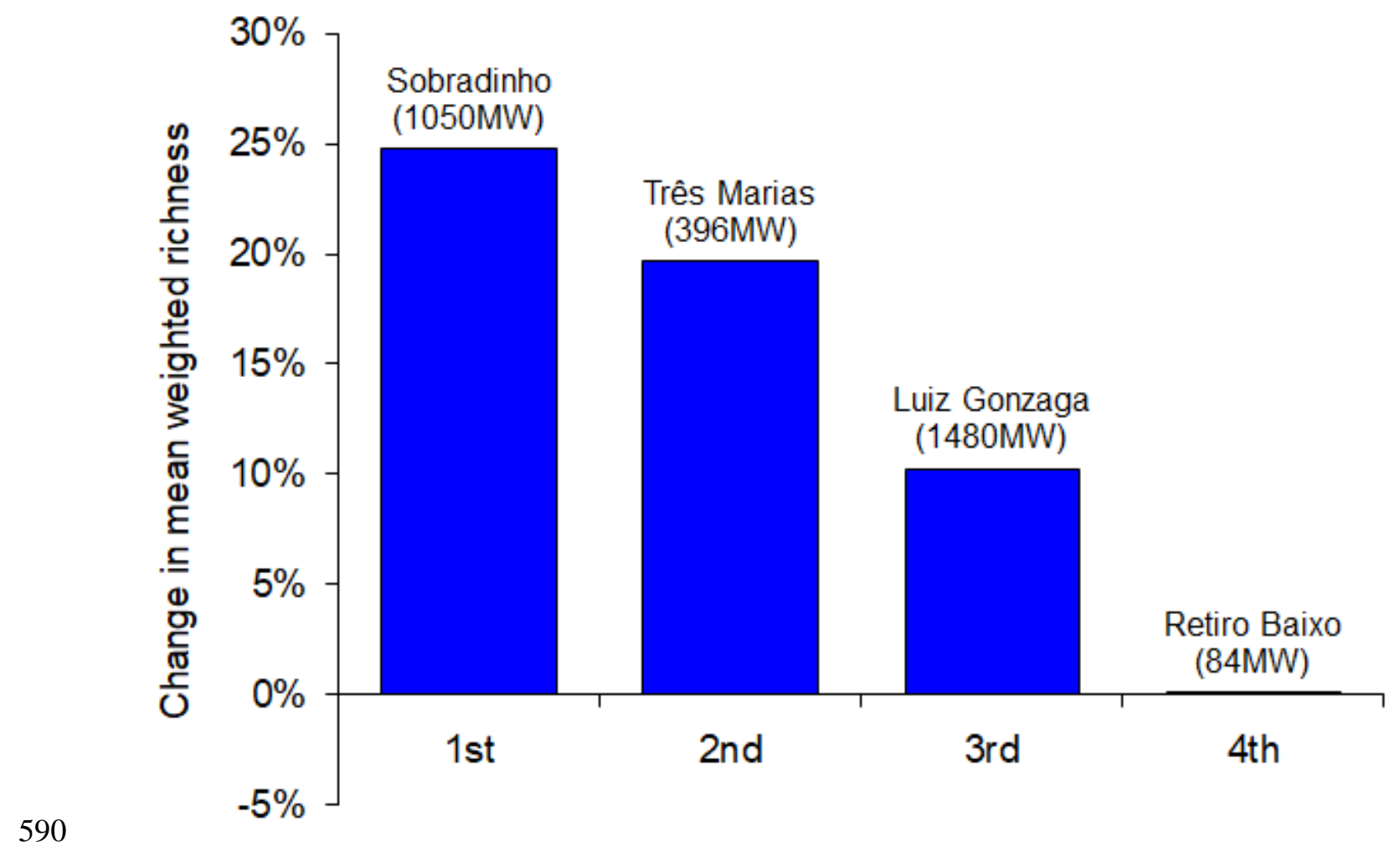

591 [Figure 6b]

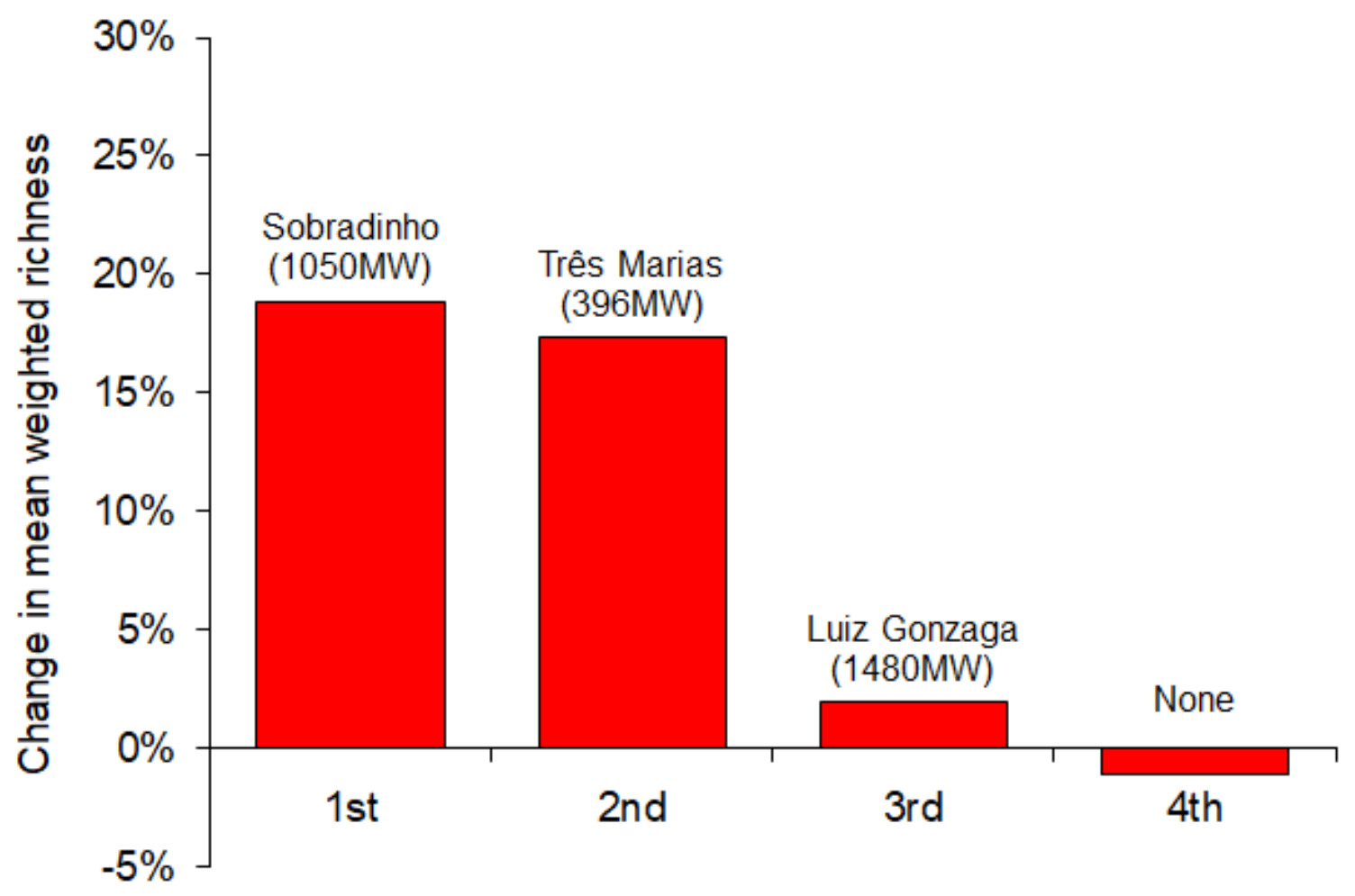

